Vol. 14 No 1 Juni 2019, hal. 29-37

\title{
MENINGKATKAN KETERAMPILAN SHOOTING BOLA BASKET DENGAN KONSEP BEEP PADA SISWA SMP
}

\author{
Isdwimanto \\ isdwimanto@gmail.com \\ SMP Negeri 1 Pringgasela
}

\begin{abstract}
This study aims to describe the extent of improvement in basketball shooting skills with the BEEF concept in students of class VII 6 of SMP Negeri 1 Pringgasela. This study uses a qualitative approach and the type of research conducted is classroom action research. This research was conducted in SMP Negeri 1 Pringgasela. in 2 cycles. The results of this study indicate that on the first cycle there is an increase based on the pretest value obtained but not too significant so that it is resumed in cycle II to be improved with significant results on basketball shooting skills with the BEEF concept. Obtained an increase in each cycle already above $15 \%$ with an average increase for all compones of $30.35 \%$.
\end{abstract}

Keywords: basketball shooting skills, BEEF concept

\begin{abstract}
Abstrak
Penelitian ini bertujuan untuk mendeskripsikan sejauh mana peningkatan keterampilan shooting bola basket dengan konsep BEEF pada siswa kelas VII 6 SMP Negeri 1 Pringgasela. Penelitian ini menggunakan pendekatan kualitatif dan jenis penelitian yang dilakukan adalah penelitian tindakan kelas. Penelitian ini dilakukan di SMP Negeri 1 Pringgasela.dalam 2 siklus. Hasil penelitian ini menunjukan bahwa pada sklus I terdapat peningkatn berdasarkan nilai pretes yang didapat akan tetapi tidak terlalu signifikan sehingga dilanjutkan kembali pada siklus II untuk dilakukan perbaikan dengan hasil yang cukup signifikan pada keterampilan shooting bola basket dengan konsep BEEF. Didapat kenaikan pada setiap siklus sudah di atas $15 \%$ dengan rata-rata peningkatan untuk seluruh kompones sebesar 30,35\%.
\end{abstract}

Kata kunci: ketrampilan shooting bola basket, konsep BEEF 
Pendidikan jasmani adalah salah satu aspek atau bagian dari pendidikan secara umum. Sayangnya, baik pendidikan maupun pendidikan komparatif tidak banyak bicara tentang pendidikan jasmani. Oleh karena itu, bidang pendidikan jasmani dan olahraga telah dikembangkan oleh pendidik professional secara fisik. Sebagai studi yang sistematis dan analitis, ndidikan jasmani dan olahraga ini telah menjadi perhatiannya sendiri dan hanya mendapat perhatian ilmiah sejak Perang Dunia II. Sejumlah buku tentang sejarah pendidikan jasmani juga mencakup informasi yang bersifat komparatif, misalnya bukubuku Van Dalen, Mitchell dan Bennett (1953), Diem (1960), Legrand dan Ladegaillerie (1970), dan Wroczyriski (1985). Terlepas dari ini, bahan lain yang digunakan adalah survei, monograf, buku teks untuk kursus dalam pendidikan jasmani dan olahraga, prosiding seminar internasional, dan lain sebagainya.

Memang benar bahwa sebagian besar literatur yang berbicara tentang pendidikan jasmani dan olahraga secara komparatif tampaknya didominasi oleh Negara-negara Barat. Tetapi di luar batas negara-negara berbahasa Inggris hal-hal menarik juga telah terjadi. Misalnya, di Polandia direncanakan penelitian komparatif dimulai pada 1970-an. Pada tahun 1975, kumpulan ringkasan artikel dari sepuluh negara diterbitkan. Pada 1976 Jaworski menerbitkan buku teks pertama dalam bahasa Polandia, School Physical Education in Different Countries, di mana sistem dari 22 negara dianalisis.

Biasanya, inisiasi keolahragaan dilakukan melalui model yang dibangun untuk para profesional dan program latihan dilakukan untuk mencapai tujuan profesional secara bertahap yang dianggap umum untuk semua atlet. Para pelatih mempermasalhkan kegagalanseorang atlit dengan alasan bahwa seorang atlet tidak cukup baik, tetapi dalam kenyataannya, berkali-kali kegagalan atlet itu terletak pada salah penaganan pada proses pelatihan yang dibangun dari atlet tersebut.

Salah satu permasalahan dalam penanganan proses pendidikan jasmani di Indonesia sampai saat ini adalah belum efektifnya dan rendahnya kualitas proses pembelajaran pendidikan jasmani di sekolah. Semua ini disebabkan oleh banyak faktor diantaranya terbatasnya adalah kurang kreatifitas guru dan terbatasnya sumber-sumber belajar yang digunakan untuk mendukung proses pengajaran pendidikan jasmani. Kompetensi guru pendidikan jasmani diberbagai sekolah dan diberbagai jenjang pada umumnya kurang dikembangkan. Gaya mengajar, metode mengajar serta pendekatan yang digunakan oleh guru dalam praktek pendidikan jasmani cenderung monoton, sehingga membuat situasi, motivasi dan antusiasme siswa dalam mengikuti pembelajaran menjadi rendah.

Keaktifan siswa dalam proses pembelajaran terutama pada pembelajaran pendidikan jasmani dan olahraga sangatlah penting karena endidikan jasmani dan oleharaga mengharakpah siswa dapat memilki ketrampilan dalan setiap cabang olahraga yang diajarkan. Namun karena keterbatasan yang dimiliki oleh sekolah mengakibatkan kreatifitas seorang guru menjadi terhambat. Dalam meningkatkan kulaitas pendidikan dan pembelajaran kususnya pada mata pelajaran pendidikan jasmani dan oleharaga dapat menerapkan berbagai metode dengan berbagai media yang ada disekitarnya.

Metode dan media pembelajaran yang digunakan dalam pembelajaran hendaknya memperhatikan beberapa hal diantaranya adalah jumlah siswa, untuk melihat keaktifan siswa secara keseluruhan dalam peroses pembelajaran terutama pada praktek berolahraga dengan jumlah siswa yang banyak tentunya sangat sulit, sehingga pemilihan metode dan media menjadi sangat penting. Untuk itu seorang guru pendidikan jasmani dan olehraga harus kreatif dan selektif dalam memilih metode pembelajaran sehingga 
tujuan pembelajaran yang telah disusun sesuai dengan yang diharapkan dalam meningkatkan ketrampilan siswa.

Pengetahuan tentang fisik, teknik, dan taktik adalah sesuatu yang sangat ditekankan dalam cabang olahraga, karena seluruh proses latihan harus didasarkan pada realitas kompetisi. Khususnya dalam kaitannya dengan bola basket. Ketika seorang pemain bola basket melangkah untuk melakukan pelemparan (shooting), terkadang tidak berpikir bahwa penghitungan secara matematis itu penting misalnya seberapa besar kekuatan lemparan dengan jarak lempar, seberapa labung lemparan sehingga pas mengenai sasaran san lain sebagainya. (Imam Sodikun: 1992). Untuk lemparan bebas bola basket (shooting) menunjukkan bahwa seseorang harus menguasai hal tersebut. Kita dapat menduga bahwa beberapa pemain melakukan lemparan yang kurang baik karena mereka melempar bola pada sudut yang salah. Oleh karena itu, fokus penelitian ini adalah pelemparan bola basket (shooting), dengan konsep BEEF. (Daniel: 2017)

Pada teknik shooting dalam permainan bola basket terdapat istilah yang perlu deperkenalkan kepada siswa sejak dini yaitu BEEF. BEEF adalah sebuah konsep shooting yang memudahkan atlet untuk memahami dan menguasai teknik tembakan dengan baik dan benar. Keuntungan melakukan tembakan dengan konsep BEEF adalah efisien dan efektif mudah di mengerti. Erculj (201). Menurut Danny Kosasih (2009: 47). BEEF yaitu: (Balance) keseimbangan: Gerakan selalu dimulai dari lantai, saat menangkap bola menekuk lutut serta atur agar tubuh dalam posisi seimbang; (Eyes) mata: Agar shooting menjadi akurat pemain harus dengan segera mengambil fokus pada terget (pemain dengan cepat mampu mengkoordinasikan letak ring), dan mata tak terhalang oleh bola dan tangan; (Elbow) siku lengan: Pertahankan posisi siku agar pergerakan lengan akan tetap vertical dan (Follow through) gerakan lanjutan: Kunci siku lalu lepaskan gerakan lengan jari-jari dan pergelangan tangan mengikuti ke arah ring. (Dedy Sumiyarsono: 2002).

\section{METODE PENELITIAN}

Jenis penelitian ini adalah penelitian tindakan kelas (classroom action research) dengan pendekatan kualitatif yang terdiri dari beberapa siklus. Masing-masing siklus terdiri dari empat tahapan, yaitu: perencanaan tindakan, pelaksanaan tindakan, observasi/evaluasi, dan refleksi (Kemmis dan Mc. Taggart, 1998). Penelitian tindakan mengacu pada berbagai metode penelitian evaluatif, investigatif, dan analitis yang dirancang untuk mendiagnosis masalah atau kelemahan baik organisasi, akademik atau instruksional dan membantu pendidik mengembangkan solusi praktis untuk mengatasinya dengan cepat dan efisien. Penelitian tindakan juga dapat diterapkan pada program atau teknik pendidikan yang tidak selalu mengalami masalah, tetapi bahwa pendidik hanya ingin belajar lebih banyak tentang dan meningkatkan. Tujuan umum adalah untuk menciptakan proses pembelajaran yang sederhana, praktis, berulang, evaluasi, dan peningkatan yang mengarah pada hasil yang semakin baik untuk sekolah, guru, atau program.

Penelitian ini dilaksanakan di SMP Negeri 1 Pringgasela kecamatan Pringgasela Kabupaten Lombok Timur. Subjek penelitian adalah siswa kelas VII-6 yang terdiri dari 30 siswa. Instrumen yang digunakan dalam penelitian ini adalah Lembar observasi/pengamatan, yang berisi indikator-indikator proses pembelajaran dalam melaksanakan pengamatan di kelas. Lembar observasi yang digunakan dalam penelitian

DOI: $10.29408 /$ edc.v14i1.1277 
ini adalah lembar observasi untuk memperoleh gambaran ketrampilan shooting bola basket.

Data observasi diperoleh pada setiap tindakan untuk menilai ada perubahan peningkatan ketrampilan siswa pada setiap siklus dalam melakkan shooting bola basket. Data hasil observasi yang dilakukan akan dianalisis dengan memberikan skor untuk penentuan kategori.

$$
\text { Persentase Keberhasilan }=\frac{\sum \text { Deskriptor yang muncul }}{\sum \text { Deskriptor maksimal }} \times 100 \%
$$

Kemudian hasil perhitungan persentase keberhasilan tindakan pada masingmasing tahapan pembelajaran yang diperoleh akan dibandingkan denganpenentuan skor klasifikasi pada Tabel 1.

Tabel 1. Penentuan Skor Klasifikasi Observasi

\begin{tabular}{|c|c|}
\hline Persentase Keberhasilan Tindakan & Taraf Keberhasilan \\
\hline $85 \%-100 \%$ & Sangat Baik \\
\hline $70 \%-85 \%$ & Baik \\
\hline $65 \%-70 \%$ & Cukup \\
\hline $50 \%-65 \%$ & Kurang \\
\hline $0 \%-50 \%$ & Sangat Kurang \\
\hline
\end{tabular}

\section{HASIL DAN PEMBAHASAN}

Kegiatan awal Sebelum pelaksanaan siklus I, siswa diberikan pretes dengan tujuan untuk melihat ada tidaknya peningkatan pada siklus I. adapun hasil pretes ketrampilan shooting bola basket dapat dilihat pada Tabel 2 sebagai berikut:

Tabel 2. Hasil Pretes keterampilan shooting bola basket

\begin{tabular}{|l|l|c|}
\hline No & \multicolumn{1}{|c|}{ Uraian } & Jumlah \\
\hline 1 & Jumlah Siswa & 30 \\
\hline 2 & Yang Tuntas & 17 \\
\hline 3 & Yang Belum Tuntas & 13 \\
\hline 4 & Ketuntasan Belajar & $43,3 \%$ \\
\hline
\end{tabular}

Berdasarkan hasil pretes pada Tabel 2 di atas menunjukan bahwa ketrampilan shiting bola basket masih tegolong rendah untuk itu perlu di lakukan perbaikan dengan memberikan perlakuan pada siklus I.

\section{Siklus I}

\section{a. Perencanaan}

Tahap awal ari sikus I adalah perencanaan. Tahap perencanaan dihadiri oleh peneliti dan observer dengan agenda pembahsan RPP dan perngkat pendukung proses pembelajran dengan hasil terdapat beberapa perbaikan pada RPP yang akan digunakan yakni pada RPP belum memperlihatkan langkah-langkah penerapan metode yang digunkan secara spesifik.

\section{b. Pelaksanaan}


Pelaksanaan pembelajaran pertemuan dengan memberikan teori dan praktek teknik shooting bola basket dengan menggunakan konsep BEEF. Proses pembelajaran dimulai dengan memberikan apersepsi dan dilanjutakan dengan pemanasan. Pada pertemuan ini peneliti bersama observer mengamati cara siswa melakukan shooting bola basket dengan konsep BEEF. Siswa diberikan kesempatan untuk melakukan shooting sebanyak lima kali dengan penilaian pada ketrampilan shooting yang terakhir.

c. Observasi dan evaluasi

Evaluasi dilaksanakan pada saat praktek berlangsung dengan melihat kesesuaian teknik yang dilakukan oleh siswa bersasarkan konsep BEEF pada shooting bola basket. Berdasarkan hasil pengamatan observer masih terdapat kesalahan-kesalahan yang dilakukan oleh siswa diantaranya pada keseimbangan (Balance) yakni pada saat menangkap bola menekuk lutut serta atur agar tubuh dalam posisi seimbang; mata (Eyes) belum fokus pada terget, dan mata masih terhalang oleh bola dan tangan; siku lengan (Elbow) posisi siku kurang vertical dan gerakan lanjutan (Follow through) pada saat shooting belum kutat. Adapun hasil observasi ketrampilan shooting bola basekt dengan konsep $B E E F$ dapat dilihat pada tabel 3. Sebagai beriut:

Tabel 3. Hasil ketrampilan shooting bola basket dengan kosep BEEF

\begin{tabular}{|l|c|c|c|c|l|}
\hline \multirow{2}{*}{ Teknik } & \multicolumn{4}{|c|}{ Jumlah Siswa } & \multirow{2}{*}{ Ket } \\
\cline { 2 - 5 } & Benar & $\begin{array}{c}\text { Persentase } \\
(\%)\end{array}$ & Salah & $\begin{array}{c}\text { Persentase } \\
(\%)\end{array}$ & Cukup \\
\hline $\begin{array}{l}\text { Keseimbangan } \\
\text { (Balance) }\end{array}$ & 17 & 60.71 & 11 & 39.29 & Kurang \\
\hline Mata (Eyes) & 9 & 32.14 & 19 & 67.86 & Kurang \\
\hline Siku (Elbow) & 9 & 32.14 & 19 & 67.86 & Cukup \\
\hline $\begin{array}{l}\text { Gerakan lanjutan } \\
\text { (Follow through) }\end{array}$ & 18 & 64.29 & 10 & 35.71 & \\
\hline
\end{tabular}

Berdasarkan hasil observasi penilaian ketrampilan shooting bola basket dengan konsep $B E E F$ di atas dapat dijelaskan bahwa pada tiap komponen masih perlu perbaikan untuk sebagian besar siswa . pada tabel tersebut ketrampilan shooting bola basekt denga konsep $B E E F$ masih berada dibawah 65\%.

d. Refleksi

Berdasarkan hasil refleksi pada siklus I yang dilakukan setelah proses pembelajaran selesai oleh peneliti dan observer ditemukan bahwa pada semua komponen siswa masih banyak melakukan kesalahan terutama pada posisi mata dan siku pada saat shooting sehingga lemparan tidak mengenai sasaran selain itu sebagian besar siswa masih banyak yang bermain dan tidak memperhatikan penjelasan guru.

\section{Siklus II}

\section{a. Perencanaan}

Tahap perencanaan pada siklus II dilaksanakan dengan menyempurnakan temuantemuan atau kelemahan-kelemahan pada proses pembelajaran siklus I, yang dihadiri oleh peneliti dan kedua observer dengan penyempurnaan RPP pada teknik lemparan (shooting) sehingga siswa lebih cepat memahaminya selanjutnya memberikan motivasi kepada siswa sehingga tidak ada lagi yang bermain.

DOI: $10.29408 /$ edc.v14i1.1277 


\section{b. Pelaksanaan}

Pelaksanaan pembelajaran pertemuan 4 dilaksanakan dengan materi yang sama yakni shooting bola basket dengan konsep BEEF. Pada pertuman ini peneliti menyampaikan kembali teknik shooting bola basket berdasarkan konsep BEEF seperti pada siklus I dengan memberikan penguatan-penguatan pada komponen atau teknik yang masih kurang terutama pada posisi mata dan posisi siku. Proses pembelajaran berjalan sebagaimana yang diharapkan oleh peneliti karena sebagian besar siswa sudah memperhatikan penjelasan guru dan melakukan praktek sebagaimana yang dinstruksikan oleh peneliti berdasarkan konsep BEEF.

c. Observasi dan Evaluasi

Pelaksanaan Evaluasi siklus II dilaksanakan pada saat praktek berlangsung sebagaiman pada siklus I dengan melihat kesesuaian teknik yang dilakukan oleh siswa bersasarkan konsep BEEF pada shooting bola basket. Berdasarkan hasil pengamatan observer pada siklus II ini sudah mengalami peningkatan yang cukup signifikan dari semua komponen pada konsep BEEF shooting bola basket baik dari komponen keseimbangan (Balance) posisi mata (Eyes), posisi siku lengan (Elbow) dan gerakan lanjutan(Follow through) pada saat shooting. Adapun hasil observasi ketrampilan shooting bola basket dengan konsep $B E E F$ pada siklus II ini dapat dilihat pada tabel 4 . Sebagai beriut:

Tabel 4. Hasil ketrampilan shooting bola basket dengan kosep BEEF

\begin{tabular}{|l|c|c|c|c|c|}
\hline \multirow{2}{*}{ Teknik } & \multicolumn{4}{|c|}{ Jumlah Siswa } & \multirow{2}{*}{ Ket } \\
\cline { 2 - 5 } & Benar & $\begin{array}{c}\text { Persentase } \\
(\%)\end{array}$ & Salah & $\begin{array}{c}\text { Persentase } \\
(\%)\end{array}$ & Baik \\
\hline $\begin{array}{l}\text { Keseimbangan } \\
\text { (Balance) }\end{array}$ & 22 & 78.57 & 6 & 21.43 & Baik \\
\hline Mata (Eyes) & 23 & 82.14 & 5 & 17.86 & Baik \\
\hline Siku (Elbow) & 19 & 67.86 & 9 & 32.14 & Baik \\
\hline $\begin{array}{l}\text { Gerakan lanjutan } \\
\text { (Follow through) }\end{array}$ & 23 & 82.14 & 5 & 17.86 & \\
\hline
\end{tabular}

Berdasarkan hasil observasi penilaian ketrampilan shooting bola basket dengan konsep $B E E F$ di atas dapat dijelaskan bahwa pada tiap komponen telah mengalami peningkatan yang cukup signifikan pada setiap komponen penilaian, pada tabel di atas terlihat bahwa pada semua komponen telah menglami peningkatan di atas 65\%.

Untuk lebih jelasnya porsentase peningkatan pada setiap siklus data dilihat pada tabel 5. sebagai berikut:

Tabel 4. Peningkata ketrampilan shooting bola basket dengan kosep BEEF

\begin{tabular}{|c|c|c|c|c|c|}
\hline \multirow{2}{*}{ Teknik } & \multicolumn{3}{|c|}{ Siklus } & \multirow{2}{*}{} \\
\cline { 2 - 5 } & $\begin{array}{c}\text { Jumlah } \\
\text { siswa } \\
\text { yang } \\
\text { benar }\end{array}$ & Persentase & $\begin{array}{c}\text { Jumlah } \\
\text { siswa yang } \\
\text { benar }\end{array}$ & Persentase & Peningkatan \\
\hline $\begin{array}{l}\text { Keseimbangan } \\
\text { (Balance) }\end{array}$ & 17 & 60.71 & 22 & 78.57 & 17.86 \\
\hline
\end{tabular}




\begin{tabular}{|l|c|c|c|c|c|}
\hline Mata (Eyes) & 9 & 32.14 & 23 & 82.14 & 50.00 \\
\hline Siku (Elbow) & 9 & 32.14 & 19 & 67.86 & 35.72 \\
\hline $\begin{array}{l}\text { Gerakan lanjutan } \\
\text { Follow through) }\end{array}$ & 18 & 64.29 & 23 & 82.14 & 17.85 \\
\hline \multicolumn{7}{|c|}{ Rata-rata } & 30,35 \\
\hline
\end{tabular}

Berdasarkan tabel 5 di atas terlihat bahwa peningkatan keterampilan shooting bola basket dengan konsep BEEF pada setiap siklus sudah di atas $15 \%$ dengan rata-rata peningkatan untuk seluruh kompones sebesar 30,35\%. Karena peningtan ketrampilan shooting bola baseket dengan konsep BEEF dianggap sudah signifikan maka siklus dalam penelitian ini berakhir pada siklus II.

d. Refleksi

Berdasarkan hasil refleksi pada siklus II ditemukan dalam proses pembelajaran sudah diperbaiki pada siklus II sebagaimana temuan-temuan pada siklus I. sehingga keterampilan shooting bola basket dengan kosep $B E E F$ sebagaimana yang diperkatikan oleh siswa mengalami peningkatan sesuai dengan tujuan yang diharapkan oleh peneliti.

\section{PEMBAHASAN}

Pelaksanaan pembelajaran pada mata pelajaran pendidikan jasmani dan olahraga di SMP Negeri 1 Pringgasela selama ini masih belum maksimal hal ini dikarenakan oleh banyak faktor diatanya adalah penerapan metode pada peningkatan ketrampilan disetiap cabang olahraga yang diajarkan selain itu juga faktor yang sangat berperan alam pengikatan keterampilan berolahraga adalah faktor pendukung yakni sarana dan prasaran penunjang. Dalam penelitian ini peneliti fokus pada peningaktan ketrampilan shooting bola basket karena selama ini siswa hanya melakukan lemparan dengan tidak memperhatikan teknik yang ada yang telah diajarkan sehingga peneliti mencoba memperbaiki kesalahan-kesalahan pada teknik shooting bola basekt dengan menerapan konsep $B E E F$.

Pembelajaran dilakukan sebagaimana pembelajaran yang ada yakni dengan menmpersiapkan RPP sebagai acuan dalam mengajar dan melakuan tahapan-tahapan pembelajaran seperti tahap persiapan, pemanasan dan praktek. Pada penelitian ini peneliti melakukan analisis seberapa terampil siswa melakkan shooting bola basket dengan melakukan pretes. Hasil pretes ini yang menjadi acuan untuk peneliti melakukan tindakan perbaikan sebagaimana yang telah dijelaskan sebelumnya.

Pada siklus I pembelajaran berlangsung sebagaimana yang diharapkan hal ini ditunujkan dengan hasi observasi yang dilakukan oleh observer berdasarkan lembar observasi dan penilaian keterampilan shooting bola basket dengan konsep BEEF jika dilihat dari hasil pretes maka dapat dikatakan bahwa terjadi peningkatan pada siklus I berdasarkan hasil pretes, namun peningkatan ini belum dianggap berarti karena belum sugnifikan sebagaiman yang diharapkan oleh peneliti. Pada pelaksanaan sikls I masih terdapat kekurangan-kekurangan, berdasarkan temuan-temuan observer dan diungkapakan pada saat refleksi berlangsung, temuan-temuan pada siklus I bahwa pada semua komponen siswa masih banyak melakukan kesalahan terutama pada posisi mata dan siku pada saat shooting sehingga lemparan tidak mengenai sasaran selain itu sebagian besar siswa masih banyak yang bermain dan tidak memperhatikan penjelasan guru. Sedangkan peningkatan keterampilan shooting bola basket bersasarkan penilaian pada siklus I pada setiap komponen masih kurang

DOI: $10.29408 /$ edc.v14i1.1277 
Kekurangan-kekurangan yang ditemukan pada siklus I diperbaiki pada siklus II. Pada kegiatan perencanaan tindakan, peneliti memperbaiki tahapan-tahapan dari pembelajaran pada siklus sebelumnya, yaitu peneliti lebih memberikan kesempatan kepada siswa untuk melakukan percobaan-percobaan, peneliti menekankan pada teknik shooting yang sesuai dengan konsep $B E E F$, peneliti memotivasi siswa agar lebih aktif berlatih, dan peneliti memberikan pendalaman teknik $B E E F$. Berdasarkan hasil observasi dan penilaian teknik shooting bola basket dengan konsep BEEF pada siklus II telah mengalami peningkatan yang cukup signifikan yakni peningkatan pada setiap komponen sudah di atas 15\% sedangkan secara keseluruhan peningkatan keterampilan shooting bola basket dengan konsep $B E E F$ sebesar 30,35\% hal ini sudah berada pada kategori baik, sehingga proses penelitian berakhir pada siklus II ini.

Hasil penelitian menjukkan adanya peningkatan keterapilan shooting pada bola basket disetiap siklus, peningkatan ketrampilan shooting bola basket ini disebabkan oleh adanya perlakuan yang dilakukan oleh peneliti yakni mengubah metode latihan atau praktik shoting bola basekt dengan konsep BEEF. Konsep BEEF memberikan banyak peluang untuk siswa memahami teknik shooting secara mendalam.

\section{SIMPULAN}

Salah satu permasalahan dalam penanganan proses pendidikan jasmani di Indonesia sampai saat ini adalah belum efektifnya dan rendahnya kualitas proses pembelajaran pendidikan jasmani di sekolah hal ini dikarenakan oleh banyak faktor diatanya adalah penerapan metode pada peningkatan ketrampilan disetiap cabang olahraga yang diajarkan selain itu juga faktor yang sangat berperan alam pengikatan keterampilan berolahraga adalah factor pendukung yakni sarana dan prasaran penunjang.

Hasil penelitian menjukkan bahwa penerapan konsep BEEF pada ketrampilan shooting bola basket siswa SMP Negeri 1 Pringgasela kelas VII 6 dapat meningkat dengan cukup signifikan. Hal ini terlihat dari hasil observasi dan penilaian teknik shooting bola basket dengan konsep $B E E F$ pada siklus II telah mengalami peningkatan yang cukup signifikan yakni peningkatan pada setiap komponen sudah di atas $15 \%$ sedangkan secara keseluruhan peningkatan keterampilan shooting bola basket dengan konsep BEEF sebesar $30,35 \%$.

\section{UCAPAN TERIMAKASIH}

Peneliti mengucapkan banyak terimakasih kepada semua pihak yang membantuk terselesaikannya penelitian ini, terutama kepala SMP Negeri 1 Pringgasela yang banyak memberika supot baik berupa moril dan materiil sehingga proses penelitian tindakan ini berjalan dengan baik, bapak observer yang telah banyak membantu selama proses penelitian yang banyak memberikan saran sehingga permasalahn-permasalahan yang yang ditemukan pada saat penelitian dapat terselesaikan dan terimakasih pula kepada semua dewan guru yang memberikan supot atas erselesaikannya penelitian ini. 


\section{DAFTAR PUSTAKA}

Daniel, J. F., Montagner, P. C., Padovani, C. R., \& Borin, J. P. (2017). Techniques And Tactics In Basketball According To The Intensity In Official Matches. Revista Brasileira de Medicina Do Esporte, 23(4), 300-303. doi:10.1590/1517-869220172304167577

Erčulj, F., \& Štrumbelj, E. (2015). Basketball Shot Types and Shot Success in Different Levels of Competitive Basketball. PLOS ONE, 10(6), e0128885. doi:10.1371/journal.pone.0128885

Sumiyarsono, Dedy. (2002). Keterampilan Bolabasket. Yogyakarta: Fakultas Ilmu keolahragaan (FIK) Universitas Negeri Yogyakarta UNY.

Sodikun, Imam. (1992). Olahraga Pilihan Bola basket. Surakarta: Cetakan Pertama. Era Intermedia.

Ismiryati. (2006). Tes dan pengukuran Olahraga. Surakarta: Sebelas Maret University Press.

Kemmis, S 7 Mc Taggart, R. 1992. The Action Research Planner. Australia: Kompetensi Guru. Bandung: PT Remaja Rosdakarya.

Kosasih, Danny. (2008). Fundamental Basketball First Step To Win. Semarang, Karang Turi Media.

Mashuri, H. (2017, July 3). The effectiveness of basketball shooting training model on Mitchell,. T.R. (1987). People and organizaation: An introduction to organizational behavior. Singapore: Mc Graw Hill Inc

DOI: $10.29408 /$ edc.v14i1.1277 